\title{
The Role of Organizational Trauma on Silence and Organizational Cynicism in a Health Service
} Provider Center

Seyed Abbas Ebrahimi, Hooshmand Bagheri Gara Bollagh, Mohsen Eynali, Seyed Mohammad Mehdi Baki Hashemi

Faculty of Economic, Management and Administrative Sciences, Semnan University, Semnan, Iran

Article Info:

\section{A BSTRACT}

Introduction: Organizational Trauma Theory is one of the latest theories in the field of organizational behavior and management, which aims to examine the psychological and physical side effects of organizational trauma on an individual and a group of people within an organization. The purpose of this study was to study the role of organizational trauma on silence and organizational cynicism in a health service provider Center. Materials and Methods: This is an applied and descriptive study and has been performed by survey method. A questionnaire with 25 items was distributed among 150 employee of a health service provider center to examine the impact of the organizational trauma on cynicism and organizational silence. The questionnaire was designed based on Likert spectrum. Structural equations' modeling was used to analyze research data. Results: The findings show that organizational trauma affected the staffs in dimension of existence, depression, fear and anger and the organization in dimension of stress, anxiety, and intra-organizational relationships. Furthermore, the results indicate that organizational trauma has a positive and significant effect on organizational silence and cynicism. In addition, there was a positive and significant relationship between organizational cynicism and organizational silence. Conclusion: Considering the significant and positive relation between organizational trauma and organizational cynicism, organizational trauma can be considered as an important factor in the mental health of an organization. Organizational trauma increases organizational pessimism; possibly via the creation of a sense of inequality and justice among employees.

Key words:

1. Health Services

2. Depression

3. Fear

4. Anxiety

*Corresponding Author: Mohsen Eynali

E-mail:m_eynali@semnan.ac.ir 
نقش تروماى سازمانى بر سكوت و بدبينى سازمانى در يك مركز ارائه دهندهُ خدمات سلامت

سيد عباس ابر اهيمى، هوشمند باقرى قرهبلاغ، محسن عينعلى"، سيد محمد مهدى باكى هاشمى

دانشكده اقتصاد، مديريت و علوم ادارى، دانشعاه سمنان، سمنان، ايران

كليد وازمها:

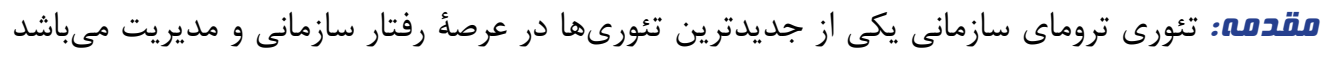

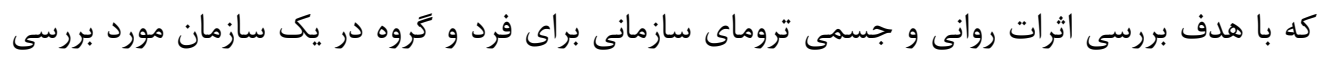

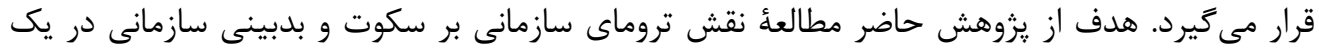

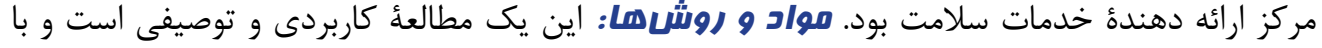

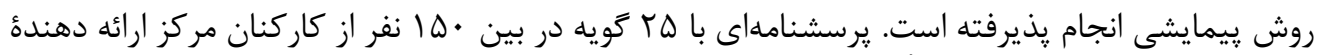

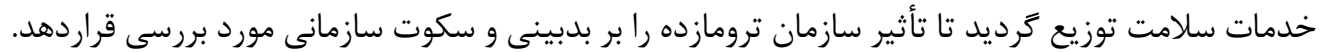

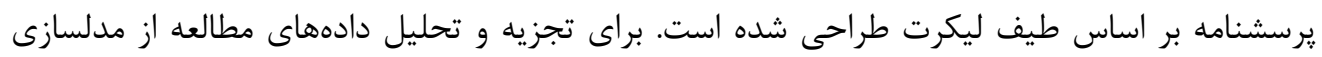

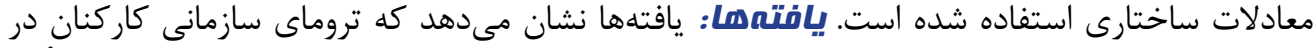

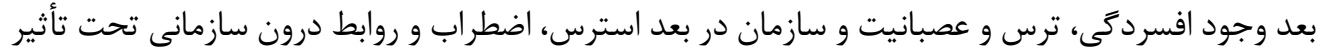

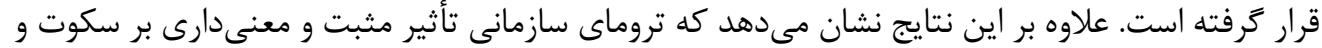

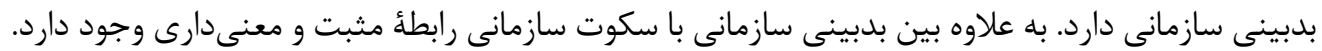

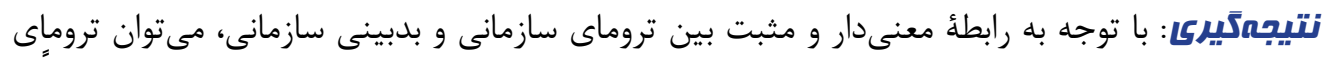

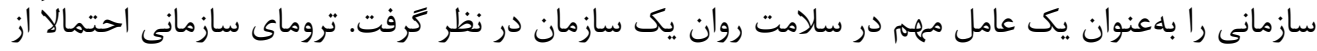

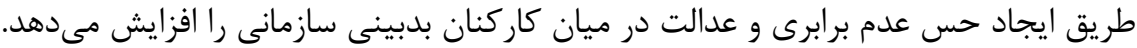

(1) إندمات سلامت

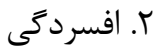

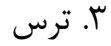

F

" نويسنده مسئول: محسن عين على : نو

آدرس الكترونيكى: m_eynali@semnan.ac.ir 


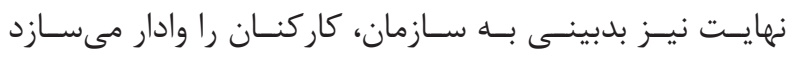

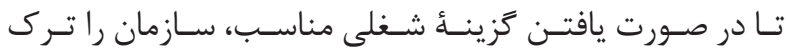

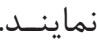

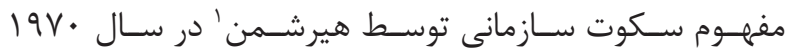

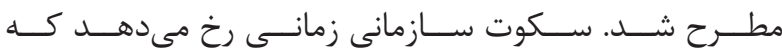

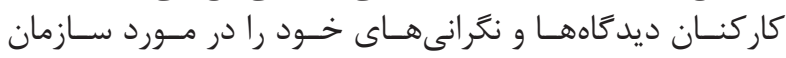

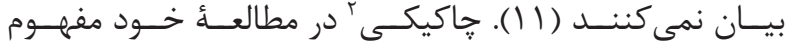

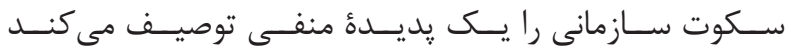

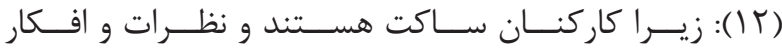

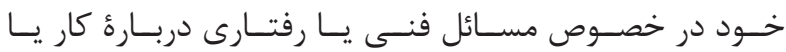

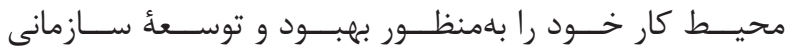

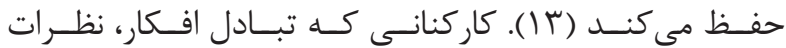

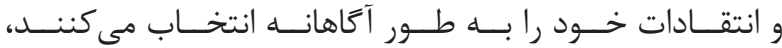

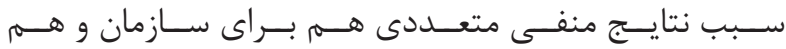

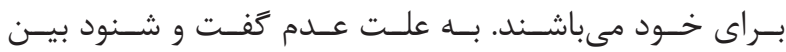

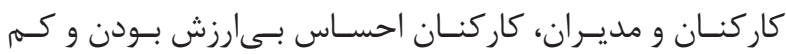

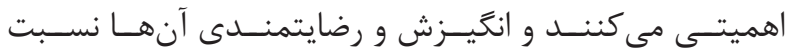

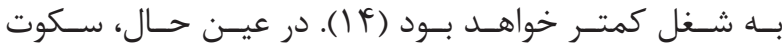

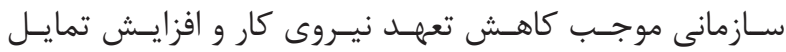

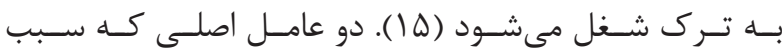

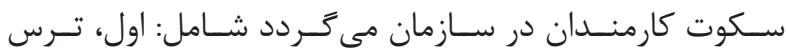

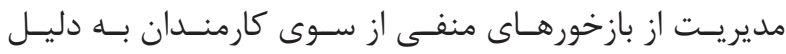

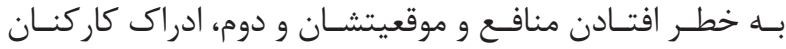

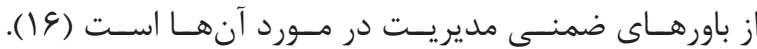

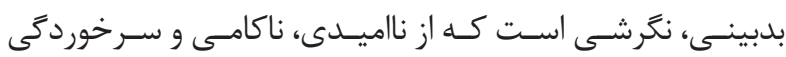

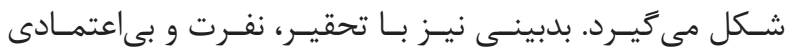

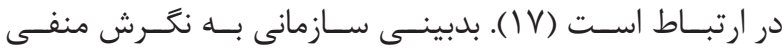

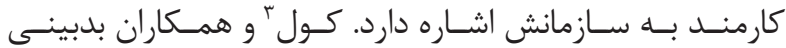

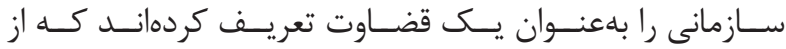

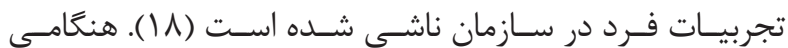

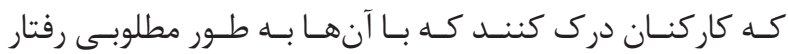

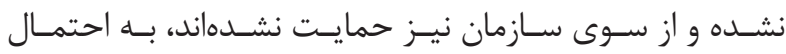

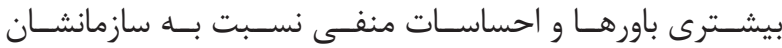

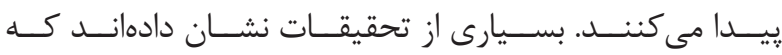

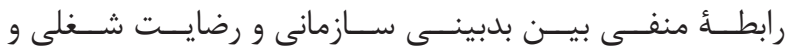

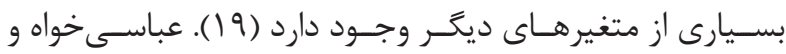

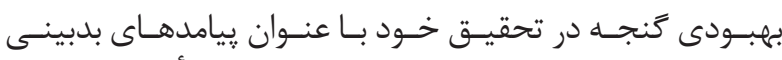

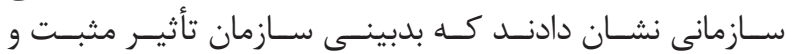

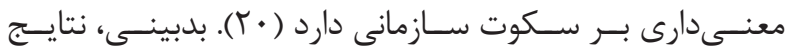

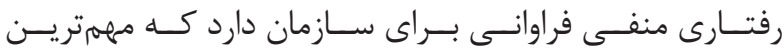

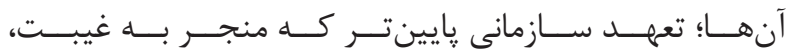

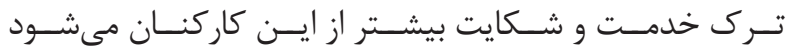

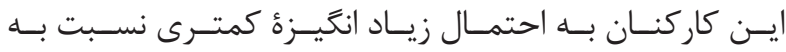

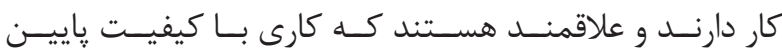

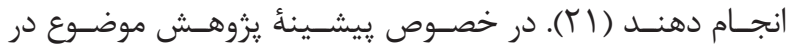

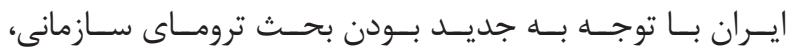

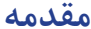

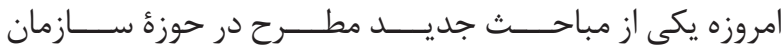

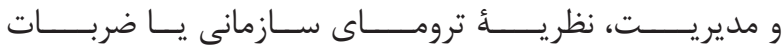

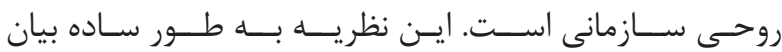

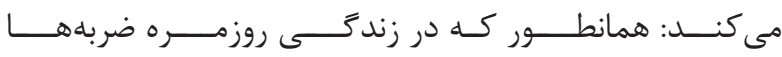

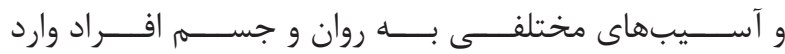

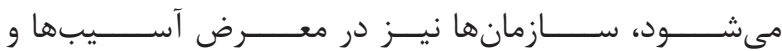

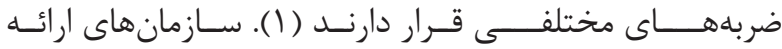

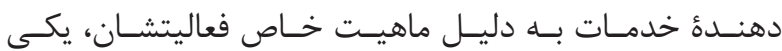

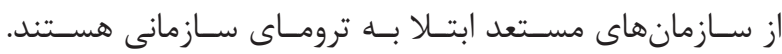

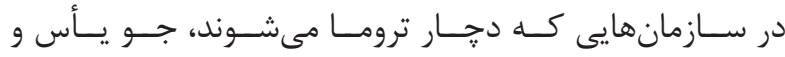

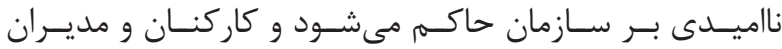

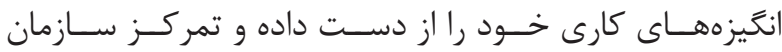

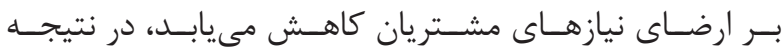

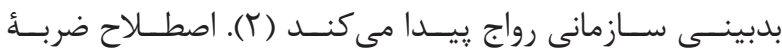

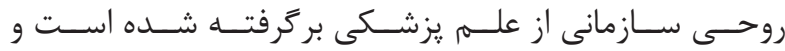

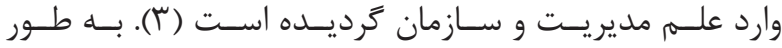

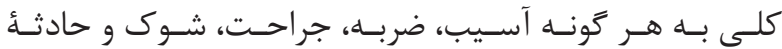

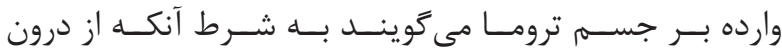

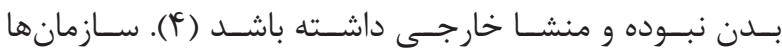

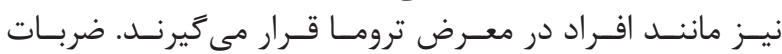

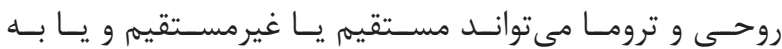

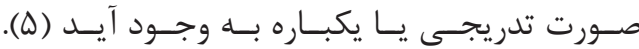

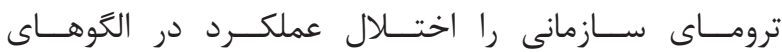

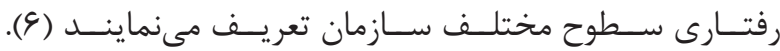

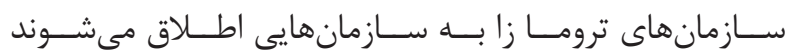

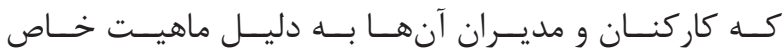

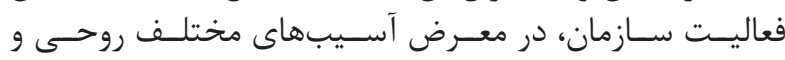

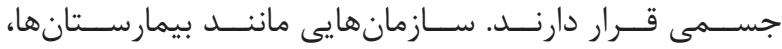

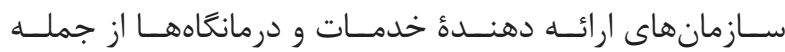

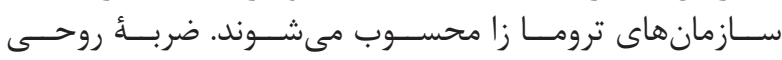

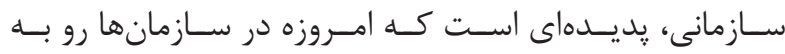

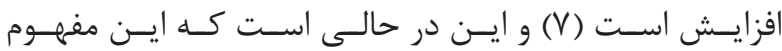

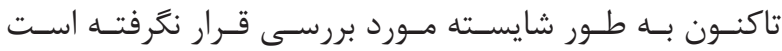

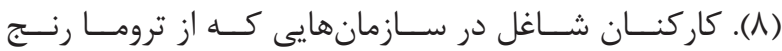

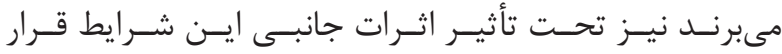

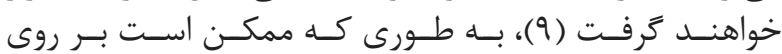

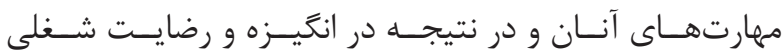

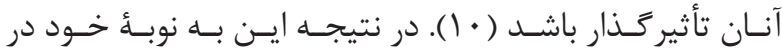

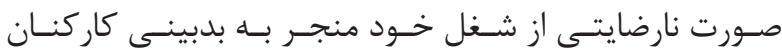

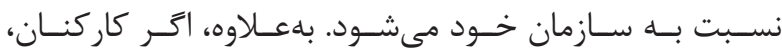

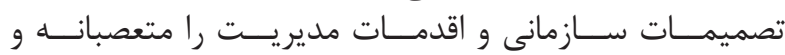

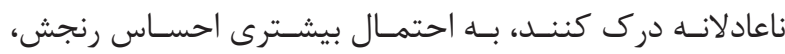

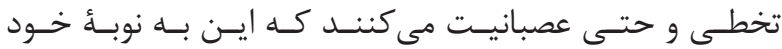

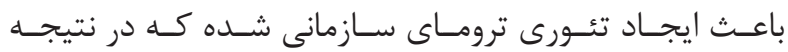

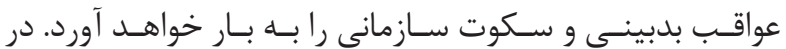

${ }^{1}$ Herishman

${ }^{2}$ Çakııı

${ }^{3}$ Cole 


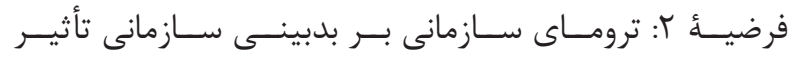
مثبـت و معنسى دار دارد.

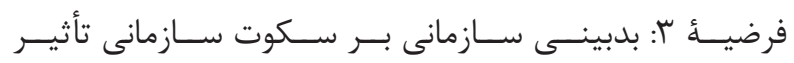
مثبـتـت و معنــى دار دارد.

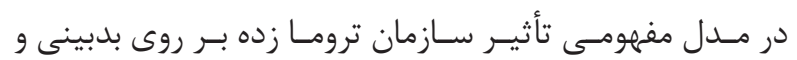

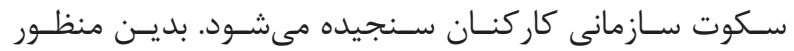

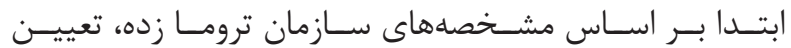

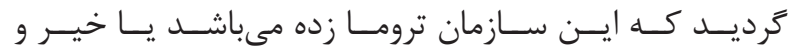

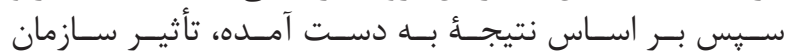

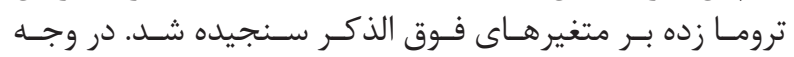

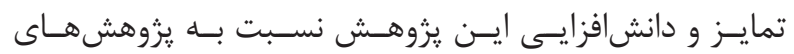

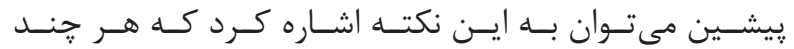

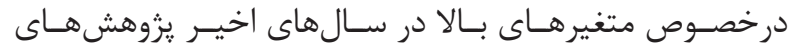

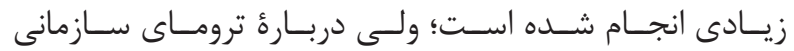

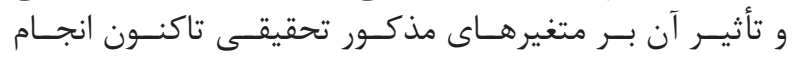

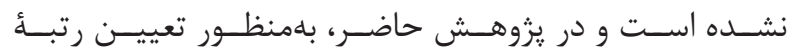

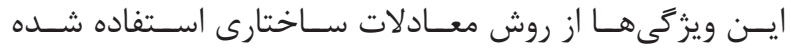

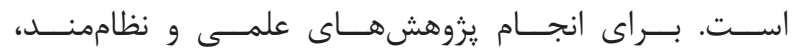

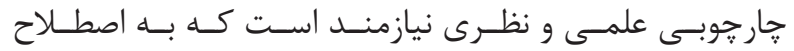

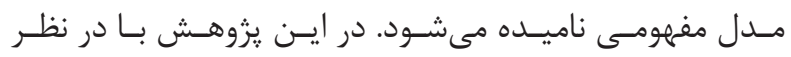

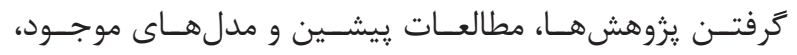

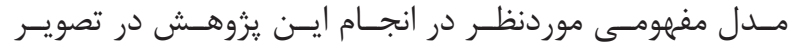

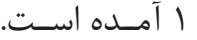

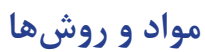

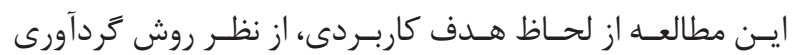

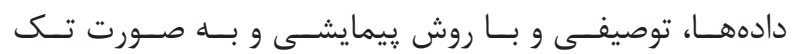

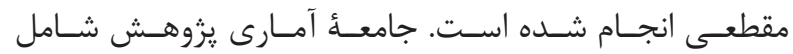

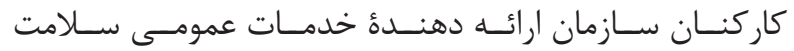

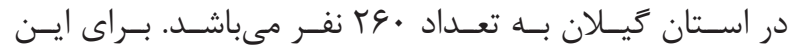

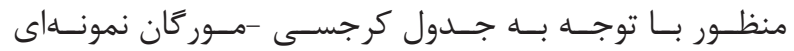

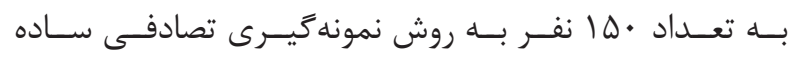

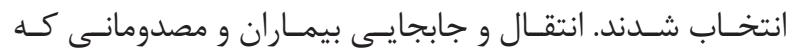

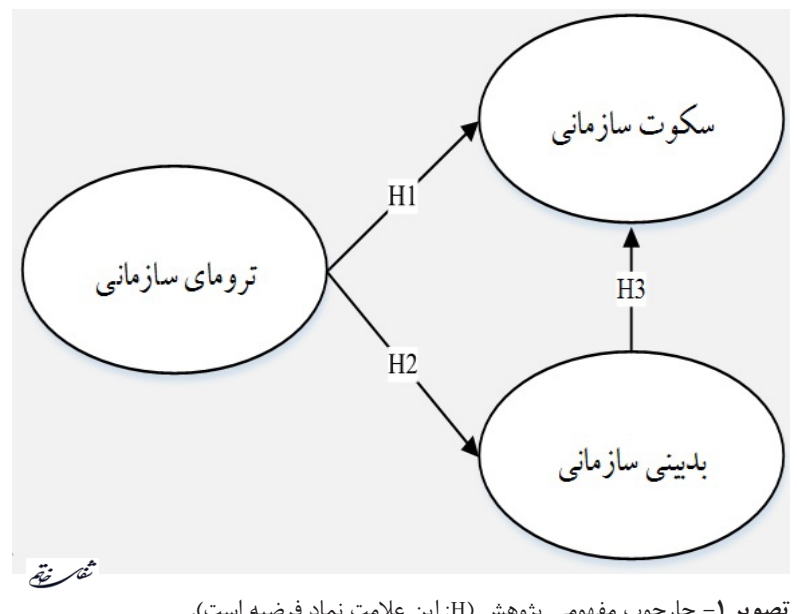

${ }^{4}$ Venugopal

${ }^{5}$ Vivan

${ }^{6}$ Fischer

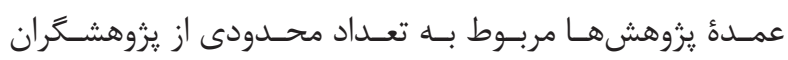

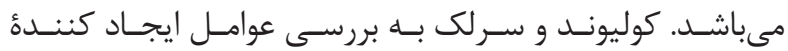

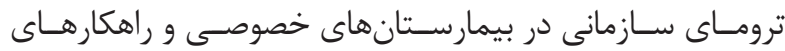

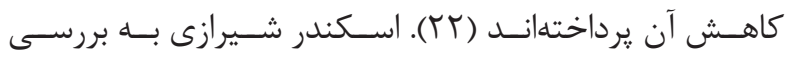

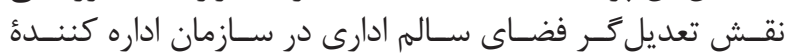

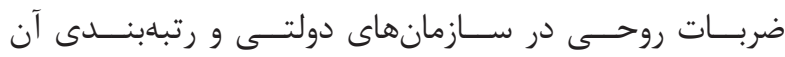

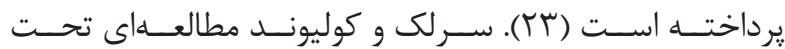

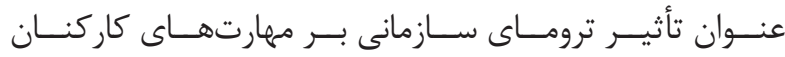

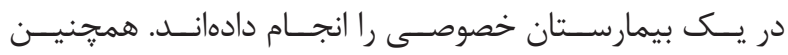

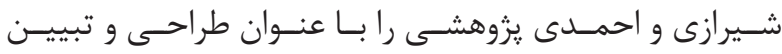

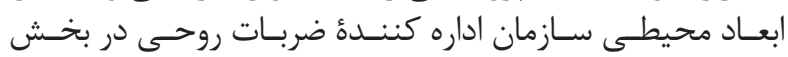

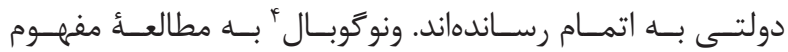

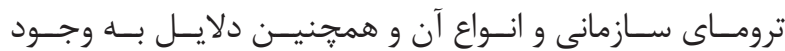

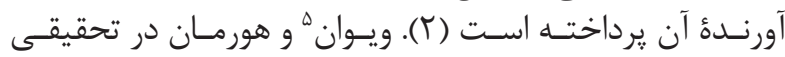

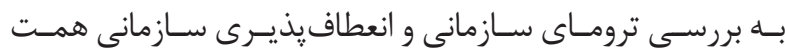

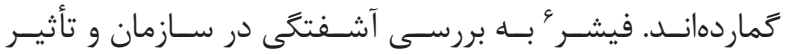

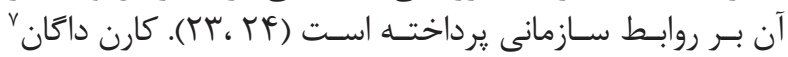

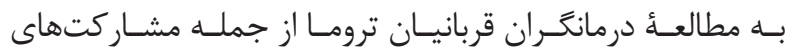

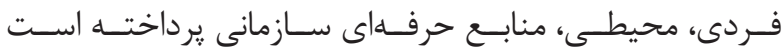

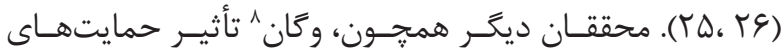

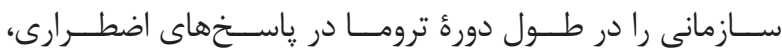

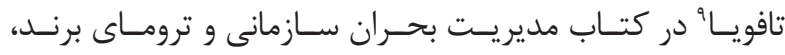

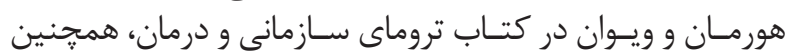

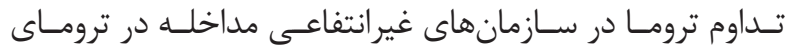

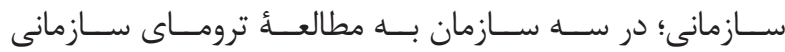

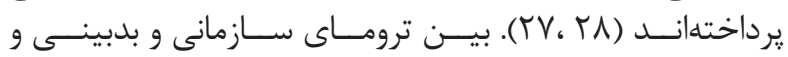

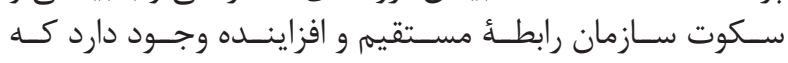

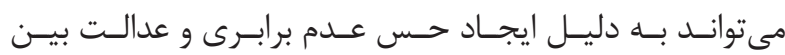

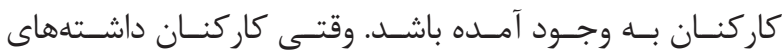

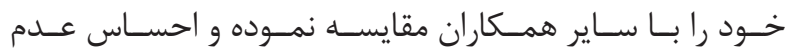

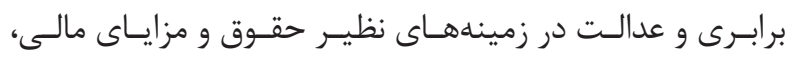

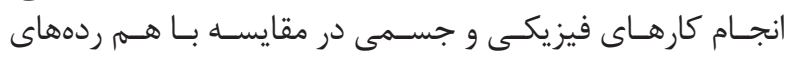

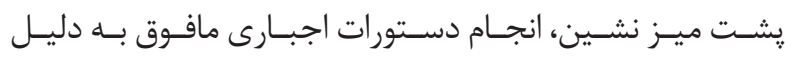

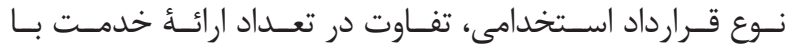

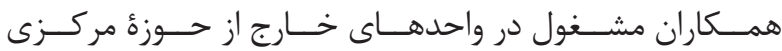

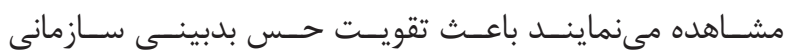

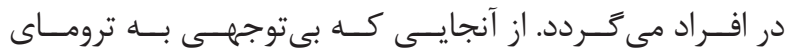

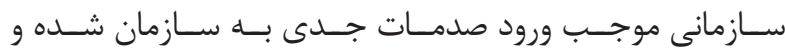

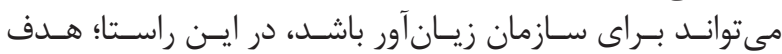

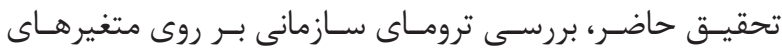

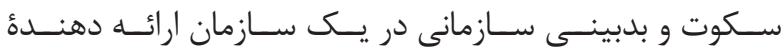

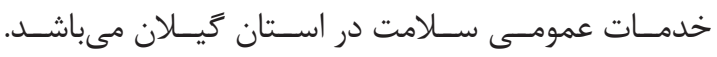

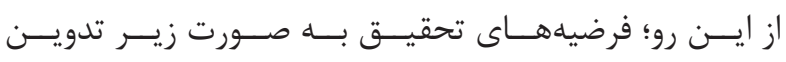
شــدهاند:

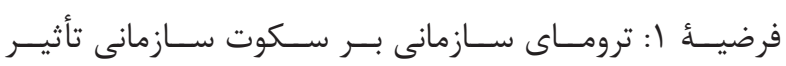
مثبــت و معنـــى دار دارد.

${ }^{7}$ Dagan

${ }^{8}$ Vaughan

${ }^{9}$ Tafoya 


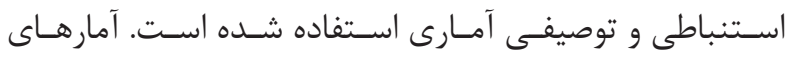

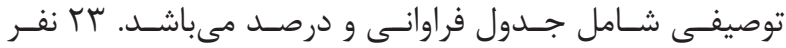

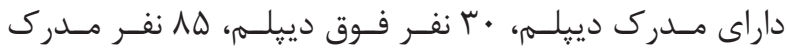

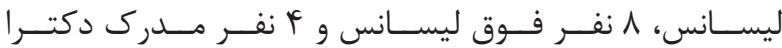

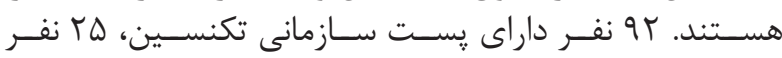

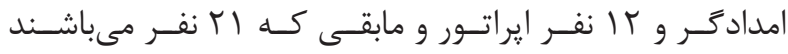

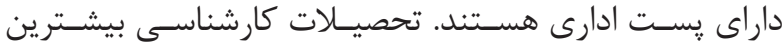

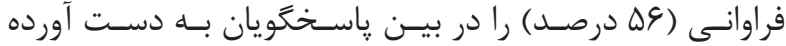

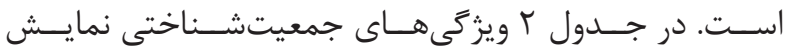
داده شـده اسـت

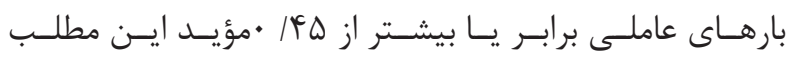

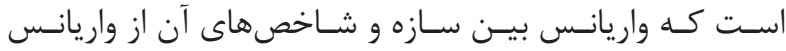

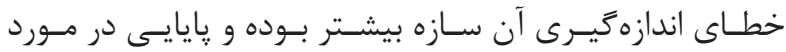

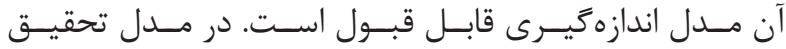

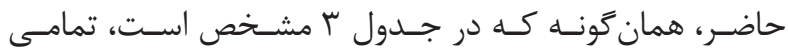

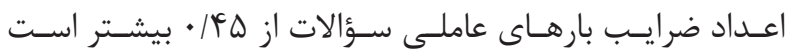

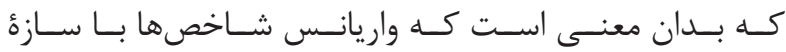

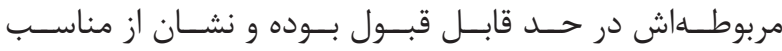

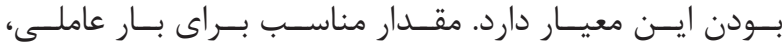

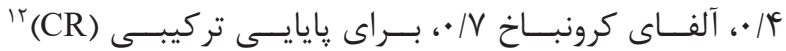

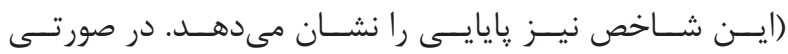

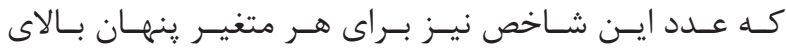

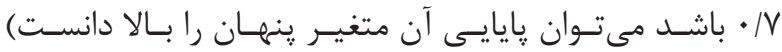

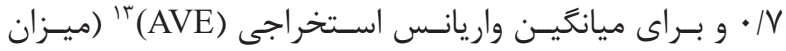

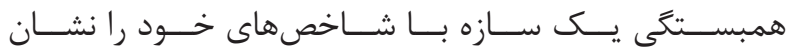

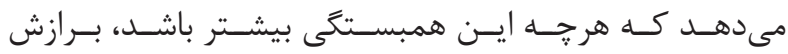

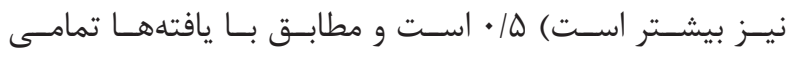

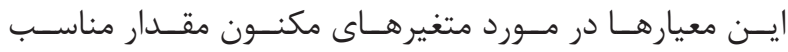

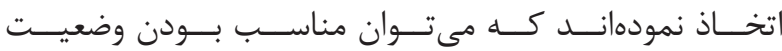

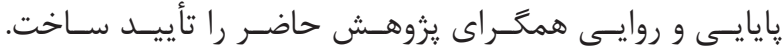

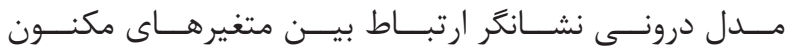

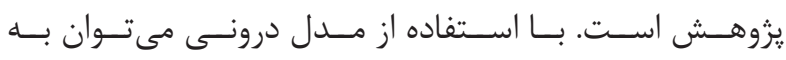

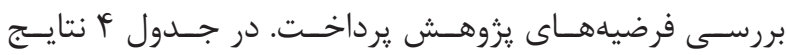

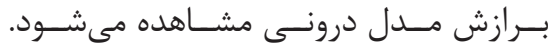

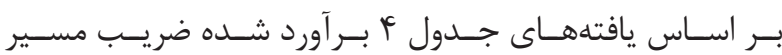

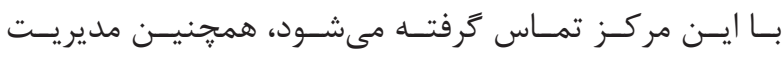

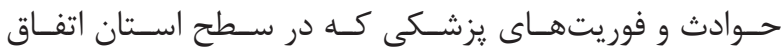

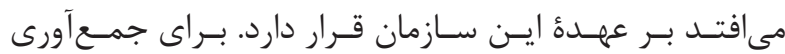

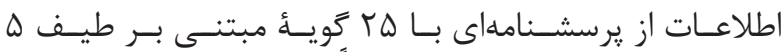

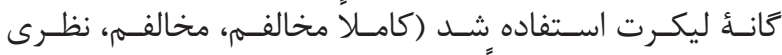

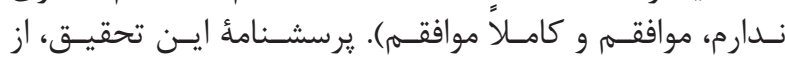

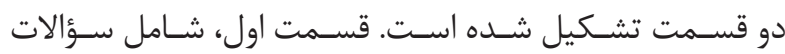

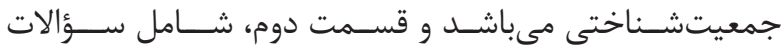

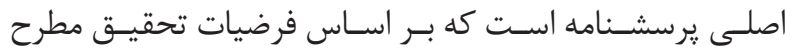

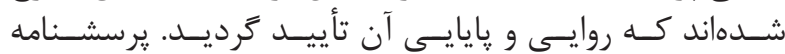

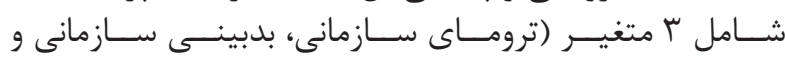

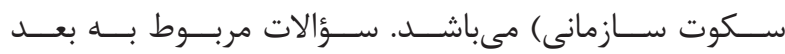

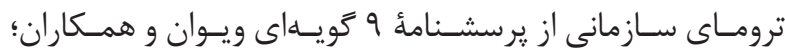

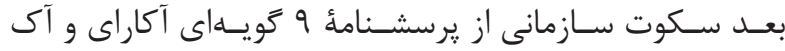

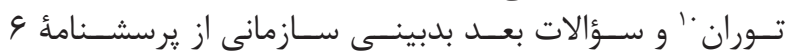

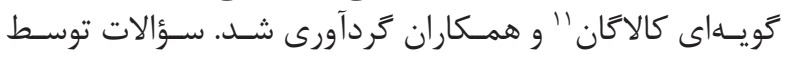

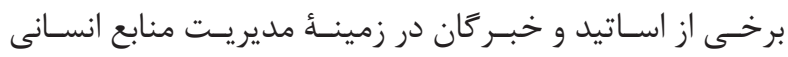

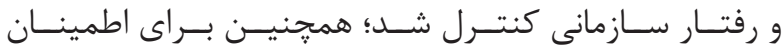

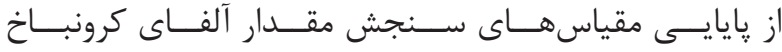

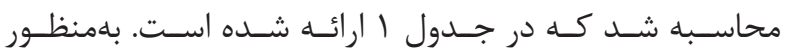

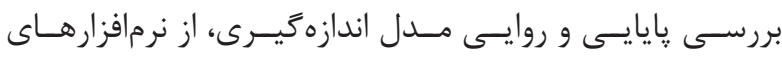

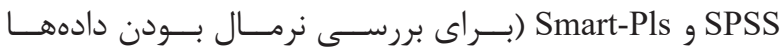

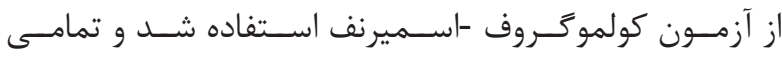

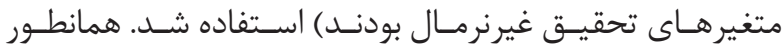

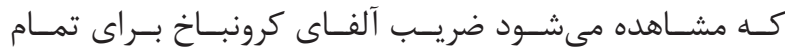

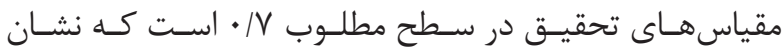

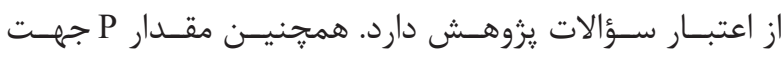

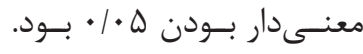

يافته ها

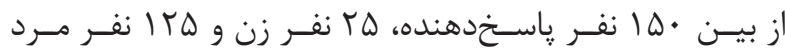

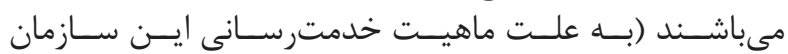

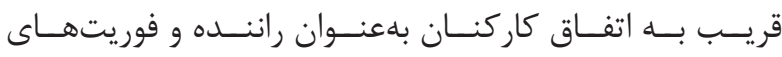

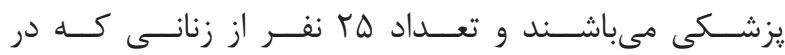

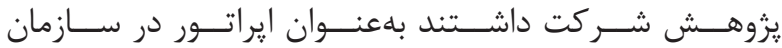

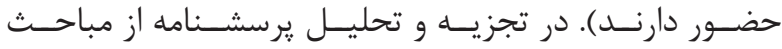

جدول ا- نتايج پايايى تحقيق.

\begin{tabular}{|c|c|c|c|c|}
\hline آلفاى كرونباخ & تعداد كويه & منبع مقياسهاى سنجش & \multicolumn{2}{|c|}{ متغيرهاى بزوهش } \\
\hline$\cdot / \wedge \Lambda$ & 9 & ويوان و همكاران، (ه • (广) & \multicolumn{2}{|c|}{ تروماى سازمانى } \\
\hline - /AV & r & آكاراى و آى توران، (ها • r) & سكوت تدافعى & \multirow{3}{*}{ سكوت سازمانى } \\
\hline$\cdot / \mathrm{Rr}$ & r & آكاراى و آى توران، (ها • & سكوت مطيع & \\
\hline$\cdot|\Lambda|$ & r & وكولا و بوراداس، (ه • ㄷ) & سكوت دوستانه & \\
\hline$\cdot 119$ & $\varepsilon$ & 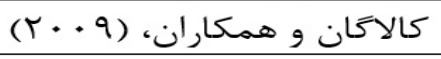 & \multicolumn{2}{|c|}{ بدبينى سازمانى } \\
\hline
\end{tabular}

${ }^{10}$ Acaray and Akturan

${ }^{11}$ kalagan
${ }^{12}$ Composite reliability

${ }^{13}$ Average variance extracted 
جدول r- ويزّكى هاى جمعيتشناختى نمونه مورد بررسى.

\begin{tabular}{|c|c|c|c|c|c|c|c|}
\hline درصد فراوانى & فراوانى & معيتشناختى & ويزگىهاي & درصد فراواتى & فراوانى & بتشناختى & ويرگى هاي \\
\hline $10 \%$ & r & ديڤِلم & \multirow{5}{*}{ تحصيلات } & $1 \mathrm{~V} \%$ & $r \Delta$ & زن & \multirow{2}{*}{ جنسيت } \\
\hline$r \cdot \%$ & $r$ r. & فوق ديیلم & & $\% \wedge r$ & ITA & 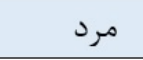 & \\
\hline$\Delta \varphi \%$ & $\Lambda \Delta$ & ليسانس & & $\Delta F \%$ & $\Lambda T$ & $1-1$ & \multirow{3}{*}{ سابقه } \\
\hline $4 \%$ & $\wedge$ & فوق ليسانس & & $r 4 \%$ & $\Delta \omega$ & $11-r$. & \\
\hline$r \%$ & $f$ & دكترا & & $\% 1$ & Ir & $r \cdot-r)$ & \\
\hline $91 \%$ & 94 & تكنسين & \multirow{4}{*}{ يست } & rr\% & $\Delta \cdot$ & rl-r. & \multirow{4}{*}{ سال) } \\
\hline$\Lambda \%$ & ir & امدادكر & & $\Delta \cdot \%$ & VQ & r-f. & \\
\hline $19 \%$ & ra & ايراتورى & & $\% 14$ & IV & $f \mid-a$. & \\
\hline $10 \%$ & rI & ادارى & & $\%$ & $\Lambda$ & $\Delta 1-G$. & \\
\hline
\end{tabular}

جدول r- شاخصهاى بايايى و روايى.

\begin{tabular}{|c|c|c|c|c|c|}
\hline 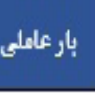 & كرونباخ & CR & AVE & to & 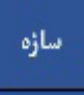 \\
\hline$+/ \mathrm{AA}_{+}$ & \multirow{6}{*}{ •/AT } & \multirow{6}{*}{$+/ \Lambda_{+}$} & \multirow{6}{*}{$+/ \Delta f$} & 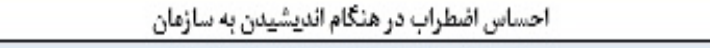 & \multirow{6}{*}{ سازيأئى } \\
\hline$+/ \wedge 9+$ & & & & احساس عصبائيت در هنثام انديشيـلان به سازئان & \\
\hline$+/ \mathrm{AA}_{+}$ & & & & وجود فاصله بين حرف تا عمل در سازمان & \\
\hline +/YAF & & & & مدم اتفاق نظردر مورد سياستها و اهداف در سازعان & \\
\hline$+/ V G A$ & & & & تعجب از انجام اتفاقى كه سازمان قصده انجام آن را ثارد & \\
\hline$+/ A \Delta T$ & & & & شكايت اتفاةات درون سازمان نزيد دوستان خارج از سازمان & \\
\hline$* / \wedge 9+$ & \multirow{9}{*}{$+/ \mathrm{AA}$} & \multirow{9}{*}{$+/ \mathrm{Y} \wedge$} & \multirow{9}{*}{$+/ \Delta 9$} & المحساس افسردئى به دليل فُشار روائق زياد و استرس & \multirow{9}{*}{ سازمائى } \\
\hline$+/ \mathrm{V} 9 \Delta$ & & & & 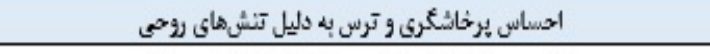 & \\
\hline$* / A T_{+}$ & & & & 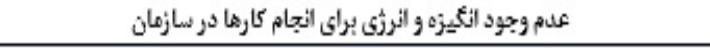 & \\
\hline$+/ \mathrm{YA}_{+}$ & & & & كمي رنأ شدن تصويرو نهنيت يبرونع نسبت به سازمان & \\
\hline$+/ \Lambda 9 \Lambda$ & & & & وبود احساسي استرس و اضطراب در هعكاران & \\
\hline.$/ 199$ & & & & شكى و ترديد در سازمان در نكاه به سازمانهاي ديكر & \\
\hline$+/ 9 \Delta \mathrm{r}$ & & & & تثويت روابط درون سائمانعى & \\
\hline + YYA & & & & عدم استعبال دريافت اطلاعات بازمخور نتايج خانج سازئمان & \\
\hline$+/$ ATE & & & & 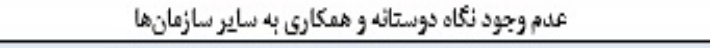 & \\
\hline$+/ \mathrm{VT \Delta}$ & \multirow{9}{*}{$+/ \mathrm{YA}$} & \multirow{9}{*}{$+/ \mathrm{Y} \Delta$} & \multirow{9}{*}{ 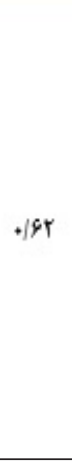 } & سريرستم از افراد مع خواهد كه اتتقاداتشان را مطرح كنند & \multirow{9}{*}{ سازمائى } \\
\hline$+/ \Lambda+\Delta$ & & & & افران رابه بيان مخالفتها و عقايد متفاوت تشويق معى كند & \\
\hline$+/ \Lambda F \Delta$ & & & & 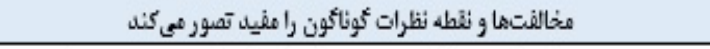 & \\
\hline$* / \Delta \Delta \Delta$ & & & & سريرسته تضادها و دعواهاي موجود در سازمان را به خروبع مديريت عق كند & \\
\hline.$/ \mathrm{99}$ & & & & 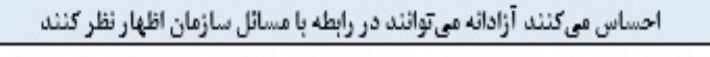 & \\
\hline$\cdot \mid \mathrm{AMA}$ & & & & 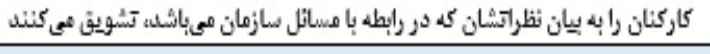 & \\
\hline+ +ห^9 & & & & 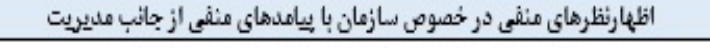 & \\
\hline$+/ V \Delta A$ & & & & مخالفتهاي خود را در رابط، با مسانل سازمان ييان كردن & \\
\hline . Arr & & & & در رايطه با مخالفتها و اعتراضات خود به سازمان وفاهارو وتعهيد نيودن & \\
\hline
\end{tabular}

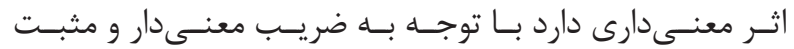

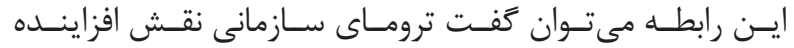

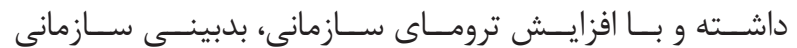

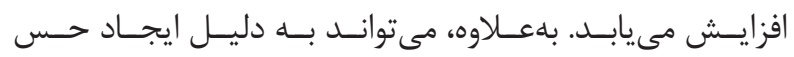

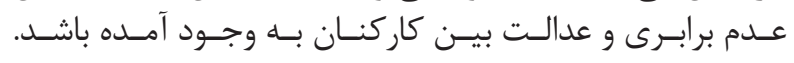

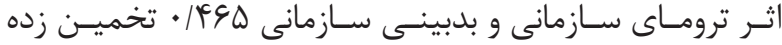

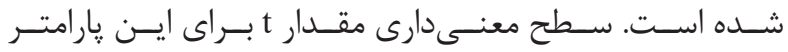

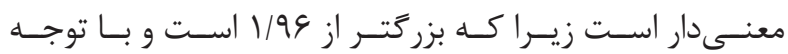

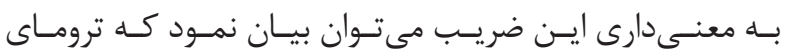

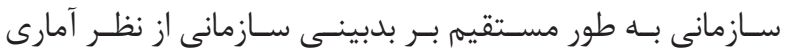




\begin{tabular}{|c|c|c|c|}
\hline نتيجهُ آزمون & 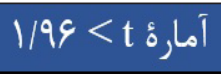 & ضريب مسير & مسير \\
\hline تأييد & $11 / 4 \Delta \varphi$ & $\cdot / \mu q$. & تروماى سازمانى ٪ سكوت سازمانى (H1) \\
\hline تأييد & $10 / 8 \wedge 9$ & $\cdot / 490$ & تروماى سازمانى † بدبينى سازمانى (H2) \\
\hline تأييد & rI/AN. & $\cdot 1 \Delta \Delta \Delta$ & بدبينى سازمانى ٪ سكوت سازمانى (H3) \\
\hline
\end{tabular}

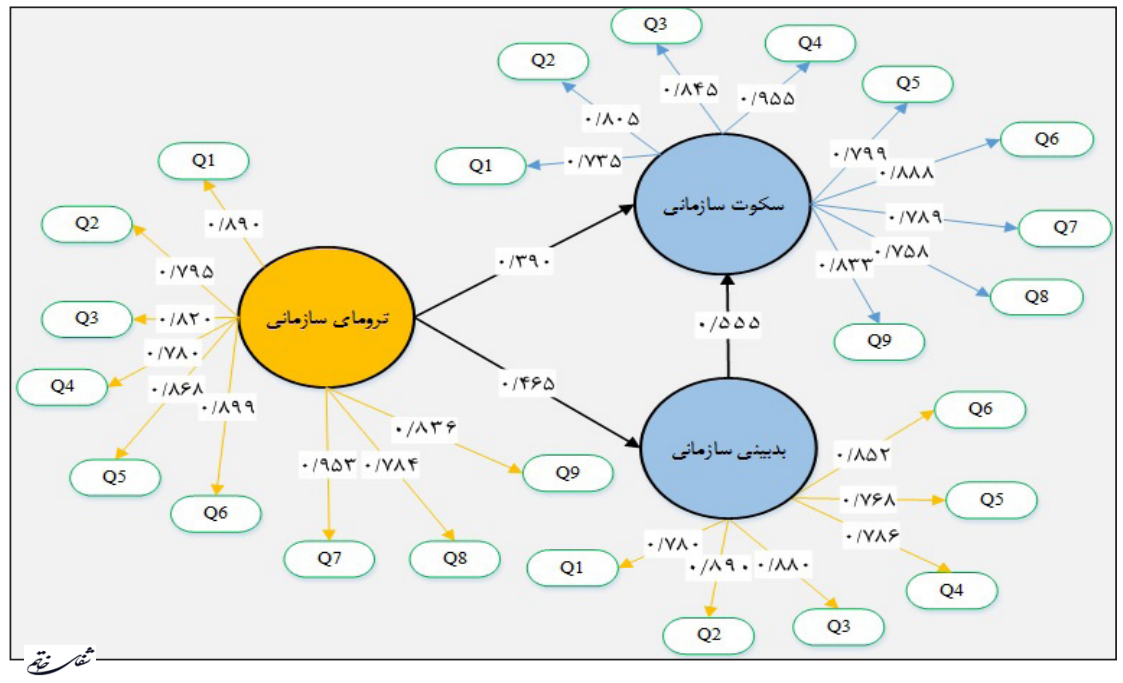

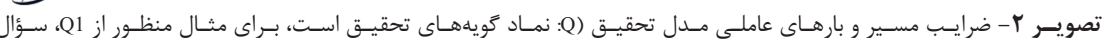

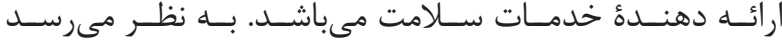

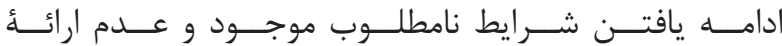

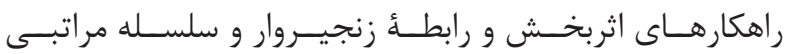

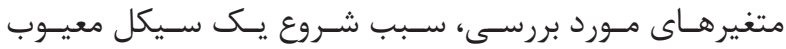

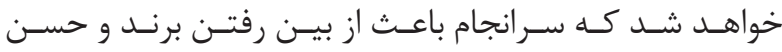

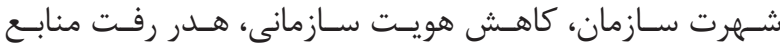

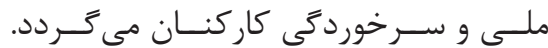

نتايسـج آزمــون نشــان داد بيــن ترومــاى سـازمانى و بدبينــى

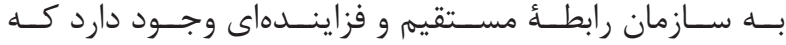

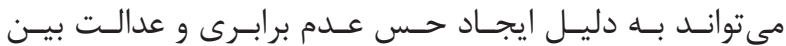

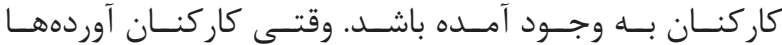

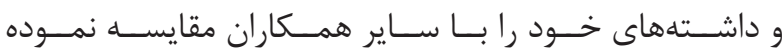

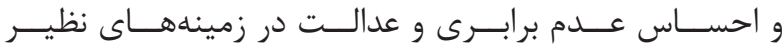

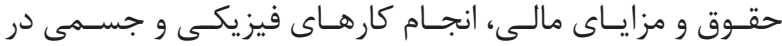

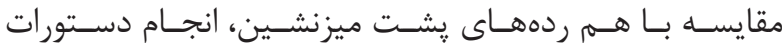

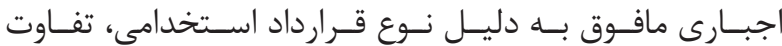

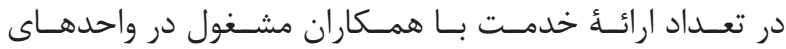

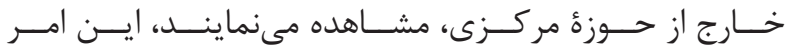

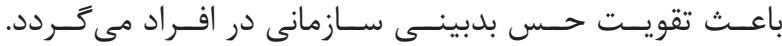

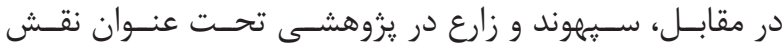

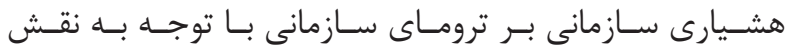

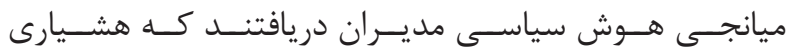

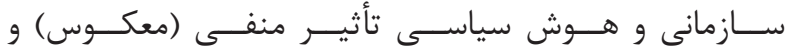

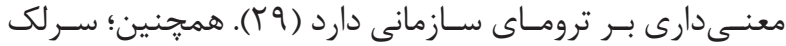

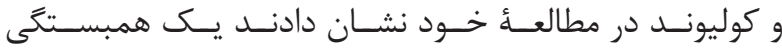

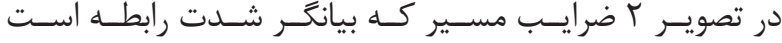

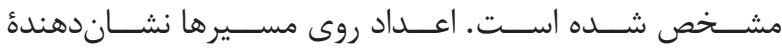

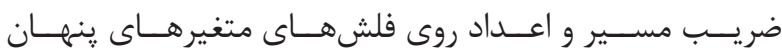

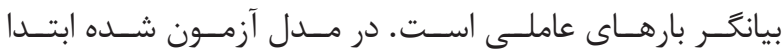

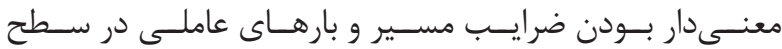

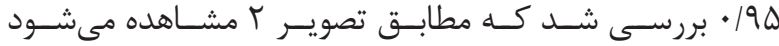

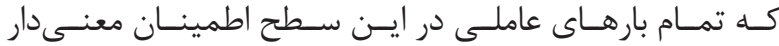

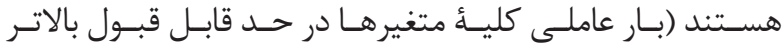

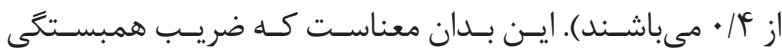

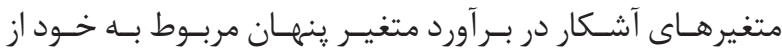

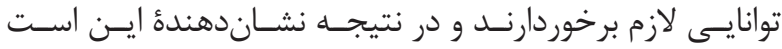

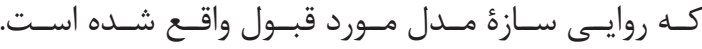
بحث و نتيجه كيرى

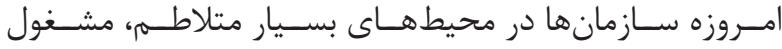

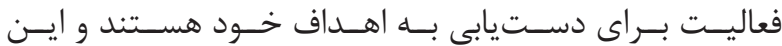

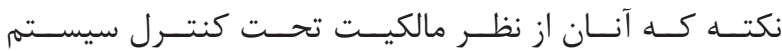

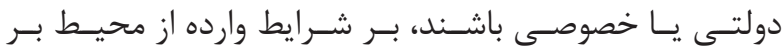

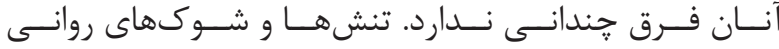

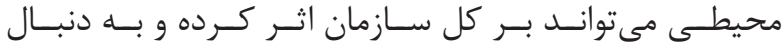

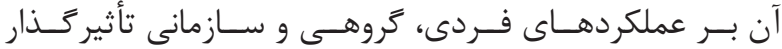

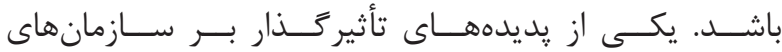

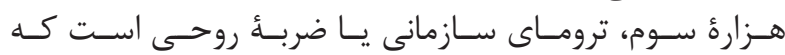

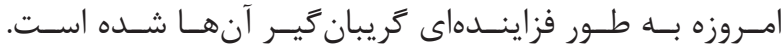

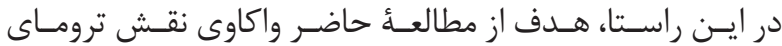

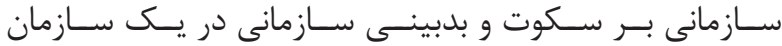




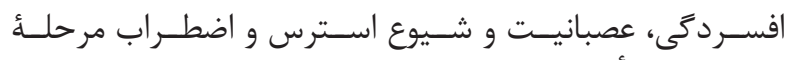

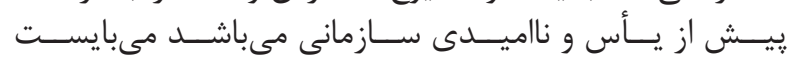

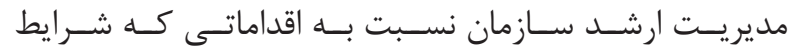

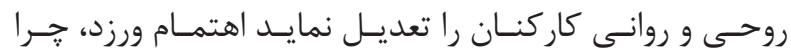

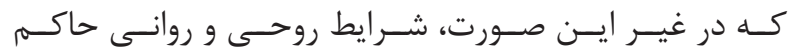

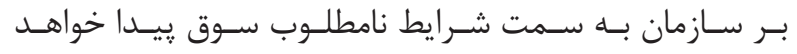

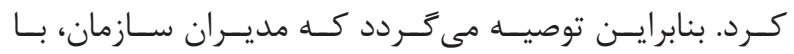

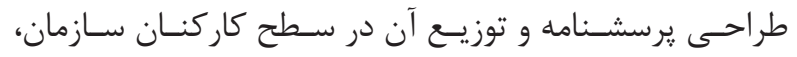

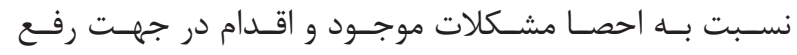

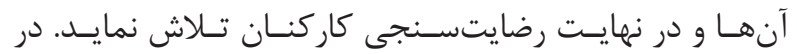

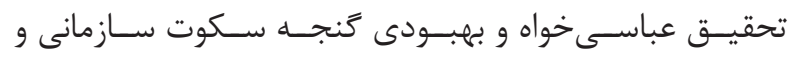

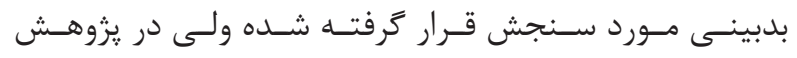

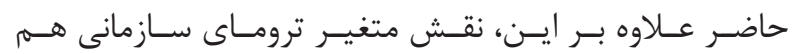

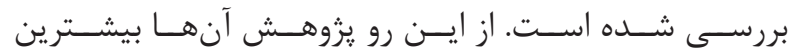

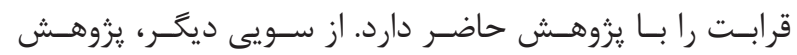

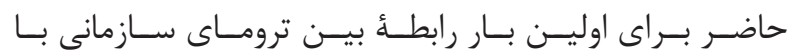

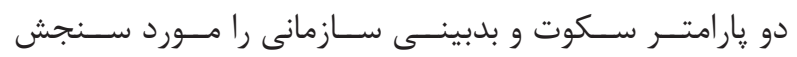

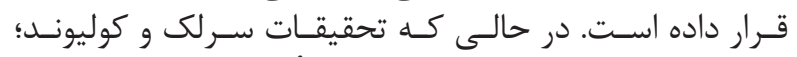

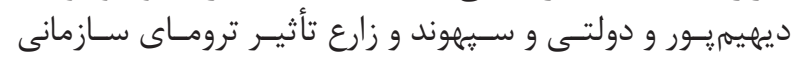

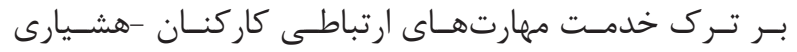

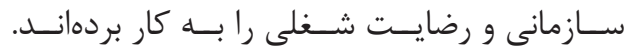

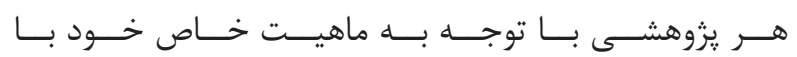

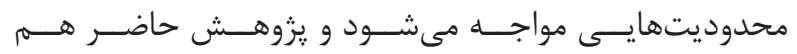

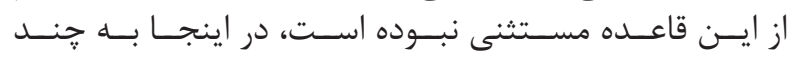

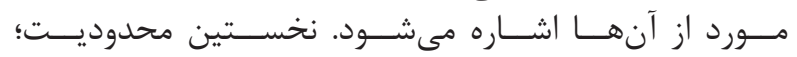

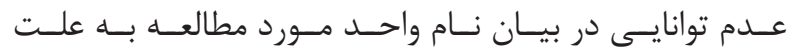

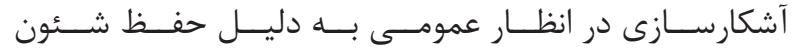

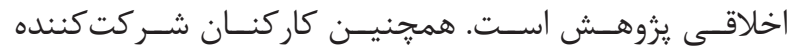

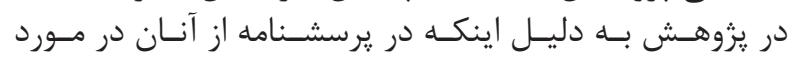

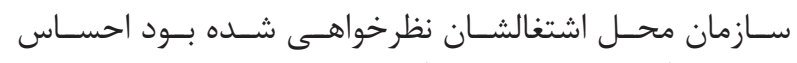

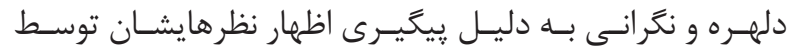

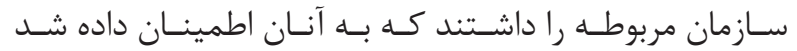

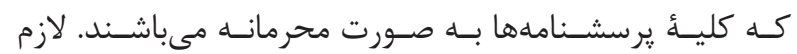

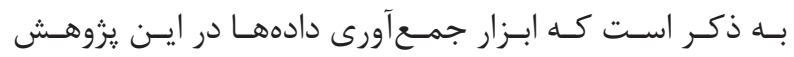

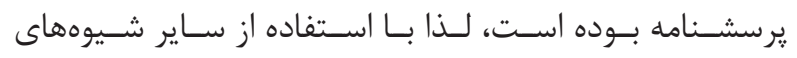

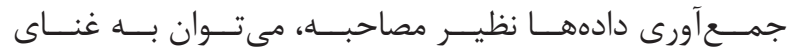

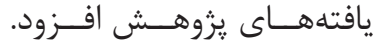

معنــى دارى بيــن ترومـاى سـازمانى و مهارتهـــاى كاركنــان

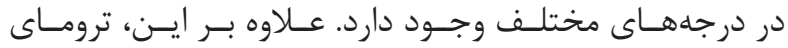

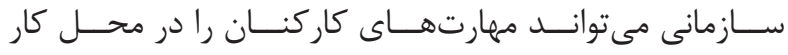

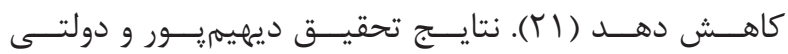

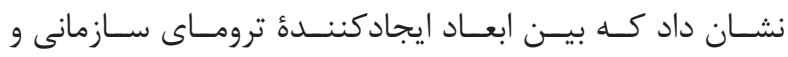

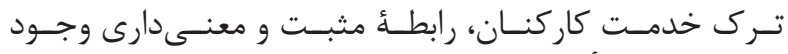

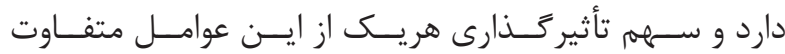

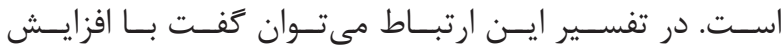

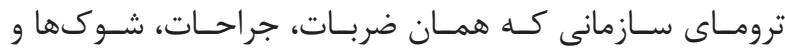

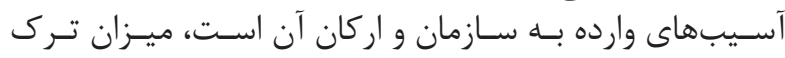

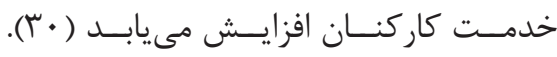

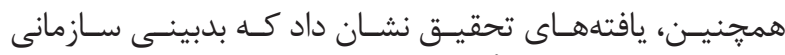

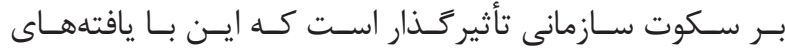

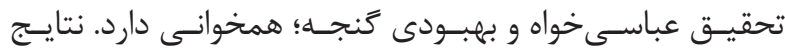

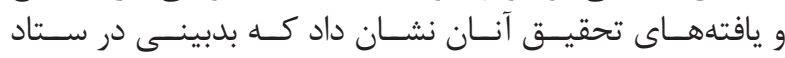

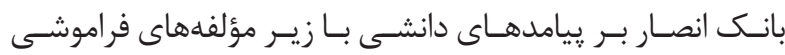

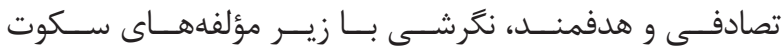

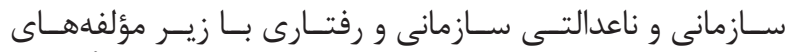

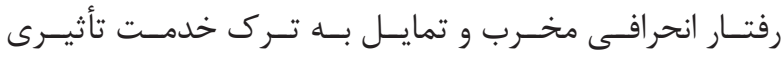

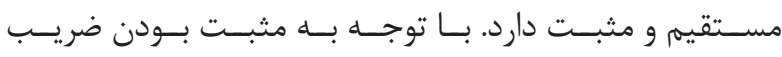

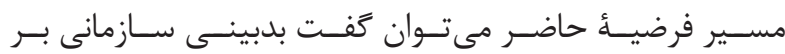

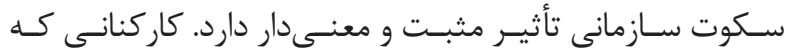

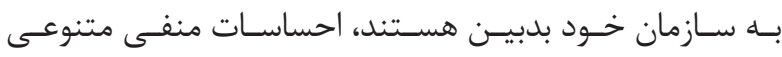

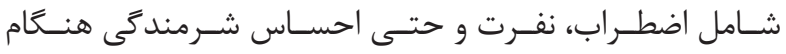

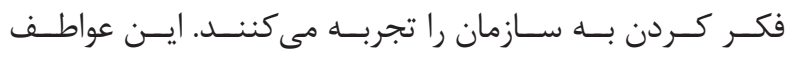

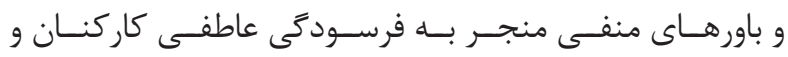

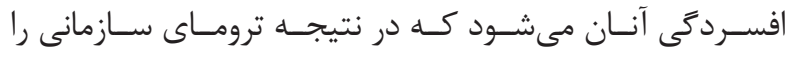
در يسى خواهـد داشـت أنسان.

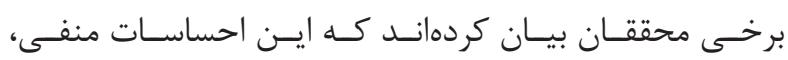

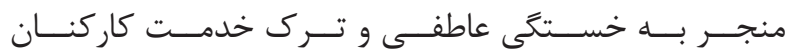

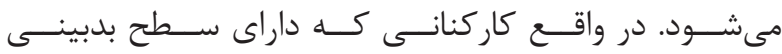

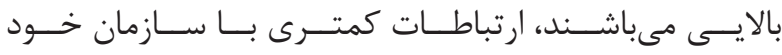

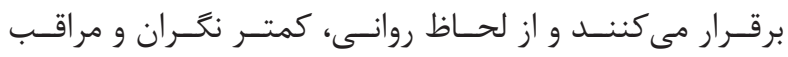

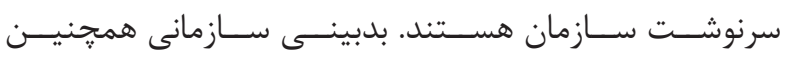

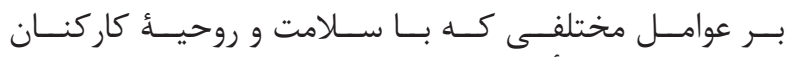

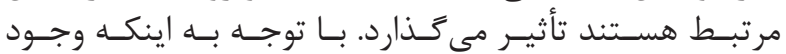


1. Abbasi Khah H, Behboodi Ganja M. The consequences of organizational pessimism (case study: ansar bank employees). Journal of Research in Management and Accounting. 2016; 2: 3 .

2. Venugopal V. Understanding organizational trauma: a background review of types and causes. Journal of Business and Management. 2016; 18(10): 65-9.

3. Kolivand P, Ali Sarlak, M. Factors of organizational trauma creation in private hospitals and solutions to decrease it case study. Shefaye Khatam. 2016; 4(1): 109-20.

4. Sarlak M-A, Kolivand P. Effects of organizational trauma on staff skills in a private hospital in Iran. Shefaye Khatam. 2016; 4(1): 45-54.

5. Hopper E. The theory of incohesion: aggregation/ massification as the fourth basic assumption in the unconscious life of groups and group-like social systems. Auestad L. Nationalism and the Body Politic. $1^{\text {st }}$ ed. Trauma and Organizations. London: Karnac Books. 2013; p. 304

6. Hormann S, Vivian P. Intervening in organizational trauma: a tale of three organizations. Leading and Managing in the Social Sector. 2015; 175-89.

7. Hormann S, Vivian P. Toward an understanding of traumatized organizations and how to intervene in them. Traumatology. 2005; 11(3): 159. doi. org/10.1177/153476560501100302.

8. Huddleston L, Stephens C, Paton D. An evaluation of traumatic and organizational experiences on the psychological health of New Zealand police recruits. Work. 2007; 28(3): 199-207.

9. Switzer, T. Recruiting after an organizational traumatic event. Organization Development Journal. 2001; 19(2), 71.

10. Muhammad AH. Procedural justice as mediator between participation in decision-making and organization citizenship behavior. International Journal of Commerce and Management. 2004; 14(3/4): 58-68.

11. Acaray A, Akturan A. The relationship between organizational citizenship behaviour and organizational silence. Procedia Soc Behav Sci. 2015; 207: 472-82.

12. Çakici A. "Örgütlerde sessizlik: sessizliğin teorik temelleri ve dinamikleri." Ç.Ü. Sosyal Bilimler Ens titüsü Dergisi. 2007; 16(1): 145-62.
13. Shojaie S, Zaree Matin H, Barani Gh. Analyzing the infrastructures of organizational silence and ways to get rid of it. Procedia Soc Behav Sci. 2011; 30: 1731-5.

14. Li X, Kan D, Liu L, Shi M, Wang Y, Yang X, et al. The mediating role of psychological capital on the association between occupational stress and job burnout among bank employees in China. International Journal of Environmental Research and Public Health. 2015; 12(3): 2984-3001.

15. Hosseini M, Sedghi Goyaghaj N, Alamadarloo A, Farzadmehr M, Mousavi A. The relationshipbetween job burnout and job performance of clinical. Journal of Clinical Nursing and Midwifery. 2017; 6(2): 59-68.

16. Cole MS, Bruch H, Vogel B. Emotion as mediators of the relations between perceived supervisor support and psychological hardiness on employee cynicism. Journal of Organnzational Behavior. 2006; 27(4): 463-84.

17. Bowen F, Blackmon K. Spirals of silence: the dynamic effects of diversity on organizational voice. Journal of Management Studies. 2003; 40(6): 1393-417.

18. Chiaburu DS, Peng AC, Oh IS, Banks GC, Lomeli LC. Antecedents and consequences of employee organizational cynicism: a meta-analysis. J Vocat Behav. 2013; 83(2): 181-97.

19. Ward KD. Cultivating public service motivation through AmeriCorps service: a longitudinal study. Journal of Administration Review. 2014; 74(1): 114-25.

20. Sepahvand R, Zare F. investigating the effect of organizational mindfulness role on organizational trauma: mediator role of managers' political intelligence. ORMR. 2018; 7(4): 95-113.

21. James MS. Antecedents and consequences of cynicism in organizations: an examination of the potential positive and negative effects on school systems. PhD Thesis. Florida State University. 2005.

22. Sarlak MA, Kolivand P. Effects of organizational trauma on staff skills in a private hospital in Iran. Shefaye Khatam. 2016; 4(1): 45-54.

23. Sarlak MA. The newfound in the twenty-first century. $1^{\text {st }}$ ed. Tehran: Marjae Danesh Publisher. 2012; p. 224.

24. Vakola M, Bouradas D. Antecedents and consequences of organizational silence: an empirical investigation. Employee Relations. 2005; 27(5): 441-58. 
25. Ahmadi F, Shirazi E. Design and explain environmental dimensions of trauma director organization in public sector. Quarterly Journal of Public Organzations Management. 2015; 3(2): 91-106.

26. Bommer WH, Rich GA, Rubin RS. Changing attitudes about change: longitudinal effects of transformational leader behavior on employee cynicism about organizational change. Journal of Organizational Behavior. 2005; 26(7): 733-53.

27. Abolghasemi S, Mahmoudi G. The effectiveness of stress immunization teaching on reducing stressful psychological feelings and blood glucose control in patients with type 2 diabetes. World Applied Sciences Journal. 2012; 17(3): 284-91.
28. Tafoya DW. Managing organizational crisis and brand trauma. Cham, Switzerland: Springer International Publishing AG. 2018; 1-15.

29. Dagan K, Itzhaky H, Ben-Porat A. Therapists working with trauma victims: the contribution of personal, environmental, and professional-organizational resources to secondary traumatization. J Trauma Dissociation. 2015; 16(5): 592-606.

30. Lambert E, Hogan NL. Jiang S. A preliminary examination of the relationship between organizational $\mathrm{s}$ tructure and emotional burnout among correctional staff. The Howard Journal of Crime and Justice. 2009; 49(2): 125-46. 